\title{
HISTOPATHOLOGICAL SPECTRUM OF SALIVARY GLAND LESIONS WITH CLINICAL CORRELATION
}

\section{DR.Radhika Mucharla \\ DR.Ravikanth Kotagiri*}

MD Pathology, Asst professor Govt medical college siddipet.

\author{
MS ENT Surgeon, Siddipet, Telangana, India ${ }^{\star}$ Corresponding Author
}

\section{ABSTRACT}

Salivary gland tumours account for $2-6.5 \%$ of all the neoplasms of the Head and Neck. Histopathology is most important in diagnosis of salivary gland tumors. AIMS and OBJECTIVES : To study age, sex and site distribution of various salivary gland lesions, to study the histomorphologic (gross \&microscopic) aspect of these lesions to correlate clinical diagnosis with that of histopathologic features. MATERIALS AND METHODS: The study is conducted in the RAINBOW CLINICAL LABORATORY AND RESEARCH CENTRE, SIDDIPET during the period of September2018 to September 2020. Formalin fixed, paraffin embedded sections and stained with hematoxylin and eosin slides were studied. RESULTS: Total number of specimens were 54. Out of these 39 were neoplastic (benign $70 \%$,malignant $30 \%$ ) and 15 were non neoplastic. Among the benign tumors majority are pleomorphic adenoma.Among the malignant tumors, mucoepidermoid carcinoma is the most common. Among the non neoplastic lesions chronic sialadenitis is most common. CONCLUSION: Histopathological examination of salivary gland lesions stands out to be the most important method in establishing the final diagnosis. It helps in differentiating non neoplastic and neoplastic lesions.

\section{KEYWORDS :}

\section{INTRODUCTION.}

Salivary glands are usually divided into Major (Parotid,Submandibular, Sublingual glands) and Minor salivary glands found in the oralcavity, nasopharynx, esophagus, larynx, trachea and bronchi.

Salivary glands are the site of origin of neoplastic and non neoplastic lesions.The histopathology of these lesions are more complex and diverse.

Salivary glands are subjected to inflammatory lesions, developmental defects and neoplasms. Salivary gland tumours account for 2-6.5\% of all the neoplasms of the Head and Neck ${ }^{1}$. Salivary gland tumors affect the Parotid $70 \%$ of cases followed by Submandibular glands $15 \%{ }^{2}$, sublingual glands $1 \%$ and minor salivary glands $5-15 \%$.Non neoplastic lesions are commonest in $3^{\text {rd }}$ decade of life. Benign tumors are common in $4^{\text {th }}$ decade and malignant tumors are usually seen from 5th decade ${ }^{(7)}$. Malignant neoplasms occur most often in males than in females ${ }^{(9)}$.

\section{AIMS AND OBJECTIVES}

1.To study salivary gland lesions in the Rainbow diagnostics during period of two years september2018- September 2020.

2.To study age, sex and site distribution of various salivary gland lesions.

3. To study the histomorphologic (gross \& microscopic) aspect of these lesions.

\section{MATERIALS AND METHODS}

The study was conducted in RAINBOW DIAGNOSTICS the department of pathology during the period of September2018 to September 2020. All the op cases in Siddipet ENT hospital ith complaint of neck swelling. A total of 54 surgically resected specimens of salivary gland lesions were analyzed. This study includes all age groups.younger age group is $10 y$ rs and older age group is $80 y$ rs. Formalin fixed, paraffin embedded sections stained with hematoxylin and eosin were studied.

\section{RESULTS}

Total 54 specimens were analyzed, Of which 39 - neoplastic, 15 - non neoplastic.Of the 39 neoplastic lesions, benign cases were 29 (74\%) followed by malignant cases 10 (26\%). In non neoplastic lesions, chronic sialadenitis - most common 9(16.7\%) In benign tumors majority - pleomorphic adenomas
26 (48.2\%).In malignant tumors, mucoepidermoid carcinoma - most common 5(9.3\%).

TABLE 1:

Incidence of salivary gland lesions

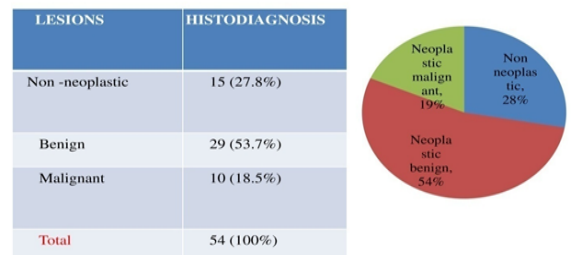

FIG 1:

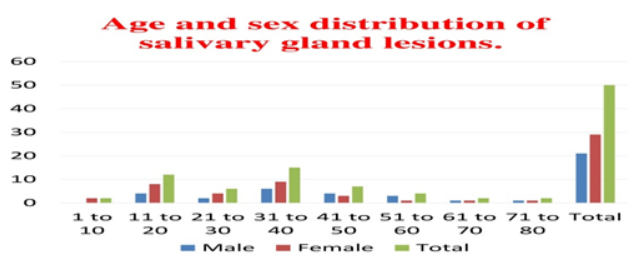

TABLE 2:

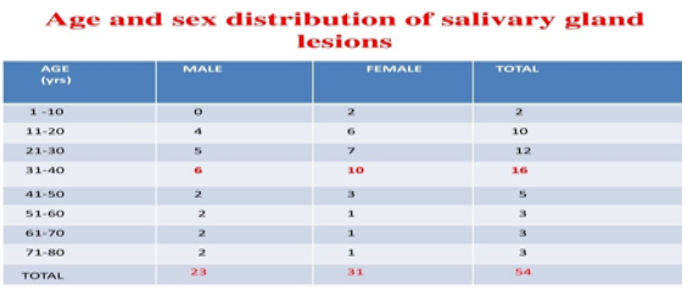

TABLE 3:

Site wise distribution of cases

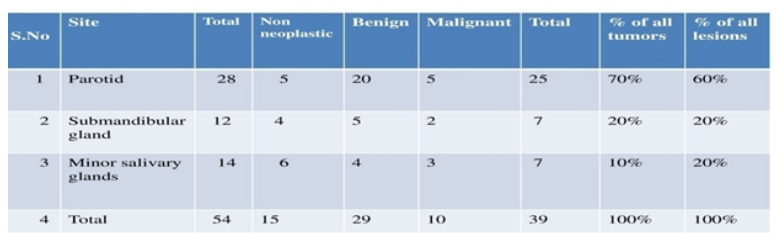

TABLE 4: 
Incidence of all salivary glands and their percentage.

\begin{tabular}{|c|c|c|c|}
\hline & SALIVARY GLAND LESIONS & $\begin{array}{l}\text { NO.OF } \\
\text { CASES }\end{array}$ & PERCENTAGE(\%) \\
\hline $\begin{array}{l}\text { NON NEEOPLASTIC } \\
\text { LESIONS }\end{array}$ & $\begin{array}{l}\text { CHRONIC } \\
\text { SIALADENITIS }\end{array}$ & 9 & $16.7 \%$ \\
\hline \multirow{5}{*}{ BENIGN TUMORS - } & MUCOCELE(SALIVARY CYST) & 6 & $11.1 \%$ \\
\hline & PLEOMORPHIC ADENOMA & 25 & $46.3 \%$ \\
\hline & $\begin{array}{l}\text { CELLULAR PLEOMORPHIC } \\
\text { ADENOMA }\end{array}$ & 1 & $1.85 \%$ \\
\hline & WARTHINS TUMOR & 2 & $3.7 \%$ \\
\hline & MYOEPITHELIOMA & 1 & $1.85 \%$ \\
\hline
\end{tabular}

TÄBLE 5:

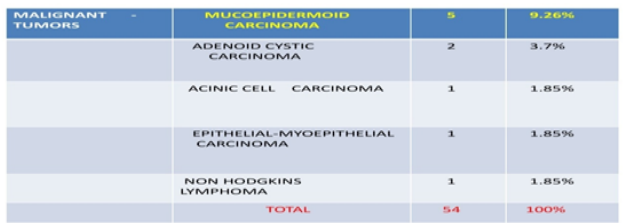

Figure 2. Gross Specimen Of parotid mass

Fig.3 Microscopic picture of Plemorphic adenoma
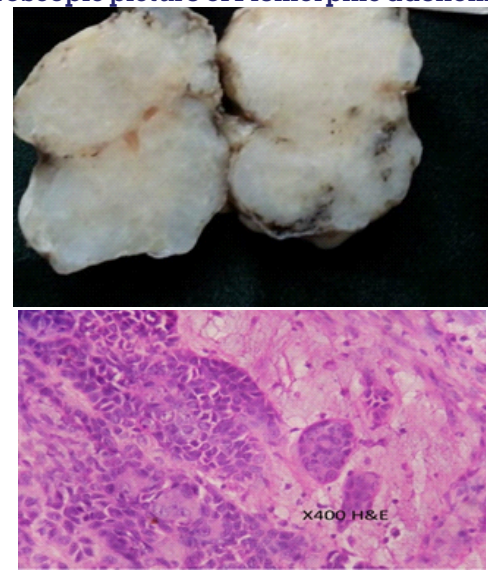

WARTHINS TUMOR Oncocytic epithelial lining,underlying ymphoid tissue with germinal centres.

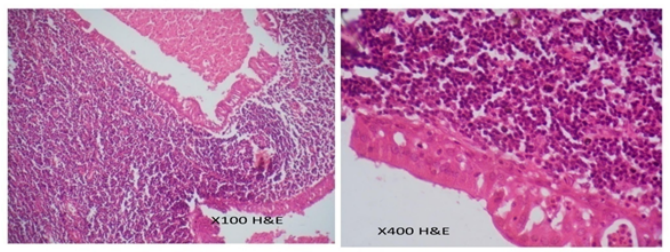

MUCOEPIDERMOID CARCINOMA

Showing mucous cells,epidermoid cells and squamous cells. Mucous cells occur in clusters.

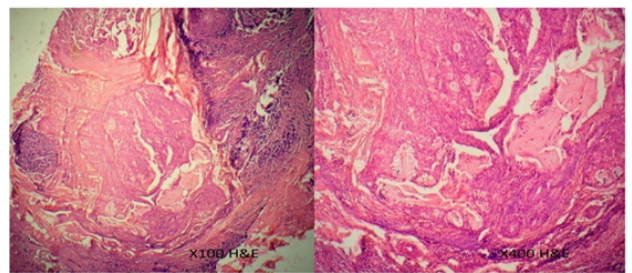

Fig: 6. Epithelial-Myoepithelial carcinoma

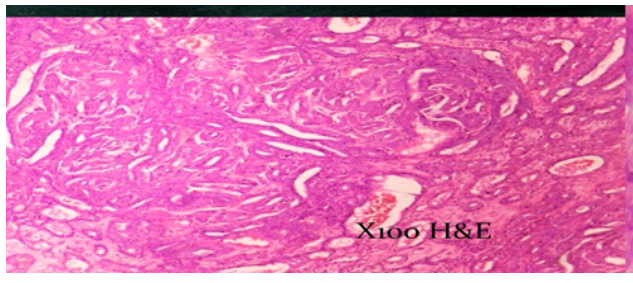

ADENOID CYSTIC CARCINOMA

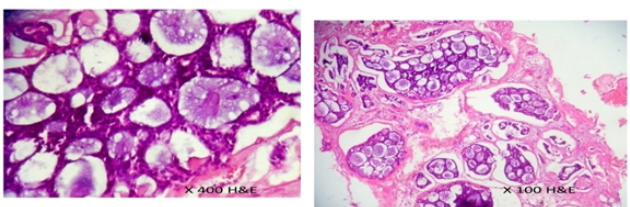

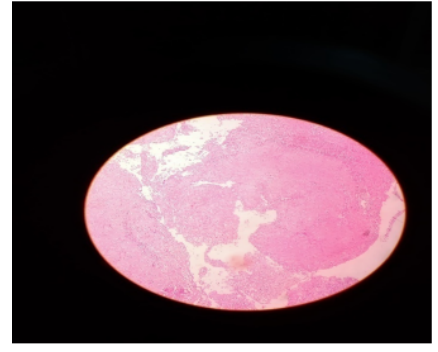

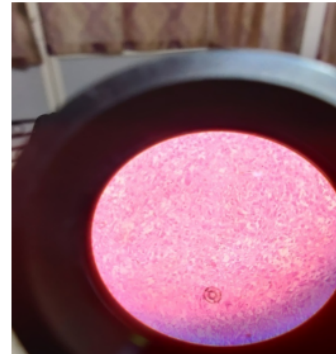

Undifferentiated carcinoma neck below ear 40 yrs male patient

\section{DISCUSSION}

Total of 54 salivary gland lesions were studied which included non neoplastic and neoplastic lesions. Out of these 54, non neoplastic lesions were $15(27.8 \%)$, benign tumors were 29 (53.7\%) and malignant tumors were 10 (18.5). The mean age of occurence was 40 yrs. Dr shazia et al (1) studied total of 80 cases which was a 10 year study, out of which 49 (61.25\%) were benign and 31 (38.75\%) were malignant. The mean age observed for all salivary gland tumor was 44.76 years. In our study there were 20 benign tumors, of which 17 were Pleomorphic adenomas, 1 case was of cellular Pleomorphic adenoma, 2 were Warthin's tumors andl case of myoepithelioma.Dr.Ankur et al ${ }^{(2)}$, studied 60 cases of salivary gland lesions. In the benign lesions, 18 were Pleomorphic adenomas, 4 were Warthin's tumors, 1 was myoepithelioma and 1 case of lymphangioma.In our study 10 malignant tumors were observed. Of which muco epidermoid carcinoma was the most common which included 5 cases, followed by 2 cases of adenoid cystic carcinomas, l case each of acinic cell carcinoma, epithelial myoepithelial carcinoma and Non Hodgkins lymphoma.Our study was comparable to Archana shetty et al ${ }^{(3)}$, which comprised of 56 cases. Of which 12 cases were malignant. Out of which 7 were Muco epidermoid and 5 were adenoid cystic carcinomas.

Mucous Extravasation Cyst : Mucous extravasation cysts occurred in younger age group between 10 to 29 years of age. Mucous extravasation cyst predominantly occurred in the lower lip (88.8\%). In $5.5 \%$ of cases it occurred in the cheek and ventral surface of the tongue respectively. In males all the cases of mucous extravasation cyst occurred in the lower lip $(100 \%)$ where as in females it was $60 \%$.

- Sialadenitis.: Inflammation of salivary glands is caused by a variety of mechanical,physical, microbial, and immunological factors.Mechanical obstruction of salivary gland ducts can lead to chronic sialadenitis.Sialadenitis was encountered in submandibular gland alone involving $40 \%$ of males and $60 \%$ of females. $20 \%$ of cases occurred in age group between 30 to 39 years of age in females. $80 \%$ of cases occurred in age group between 40 to 49 years with equal distribution in both the sexes.

- Pleomorphic adenoma is most common neoplasm of salivary glands.90\% occur in parotid gland and few in submandibulargland and minor salivaryglands. The tumor occur over a wide age range, but the peak incidence is in the 4th and 5 th decade.They present as painless, slowly growing firm mass in parotid gland, this tumor most often present in the lower ploe of parotid . Fig.2, FIG.3

Warthins tumor is 2nd most common benign tumor of parotid gland which accounts for $2-6 \%$ of all parotid neoplasms.It is also called as papillary cystadenoma lymphomatosum.It is the most common bilateral or multifocal salivary gland tumor,usually present in the sixth or seventh decade, and is associated with smoking. (FIG:4) Myoepitheliomas are benign tumors composed of myoepithelial cells. These tumors 
occurs with approximately equal frequency in the parotid gland and minor salivary glands, particularly the hard and the soft palate, and present as slowly growing painless masses in adults. Men and women are affected equally.

- Mucoepidermoid carcinoma is the most common salivary gland malignancy.Most of the cases occur in parotid gland. These tumors also arise from minor salivary glands in the oral cavity, buccal mucosa, lip.Mucoepidermoid carcinomas slightly more common in women, and the mean ge of affected patients is approximately 45 years.The tumor also occur in children. The patient usually present with a slowly growing mass.(Fig.5)

- Epithelial-myoepithelial carcinoma is a low grade carcioma that account for 0.5 to $1 \%$ of salivary gland neoplasms.It arises in the parotid gland, and occasionally arises from the minor salivary glands of larynx or paranasal sinuses.(FIG6)

Adenoid cystic carcinoma is one of the most salivary gland tumors.It comprises $10 \%$ of all salivary gland malignancies, and is the most common malignacy of the minor saliv ary glands.Although the tumor occurs in patients over a wide age range, the peak incidence is between 40 and 60 years of age.The tumor is slow growing.Perineural invasion is most common, so cranial nerve involvement including facial nerve palsy, may be the presenting symptom, with or without associated pain (Fig.7)

Acinic cell carcinoma accounts for only 1 to $3 \%$ of salivary gland tumors.It occurs evenly through the secondto seventh decades and can be seen in childhood.About $80 \%$ cases arise in the parotid gland, usually present as slow growing mass which is occasionally painful.

Undifferentiated carcinoma rare presentation at salivary glands may be primary or secondary from nasopharyngeal carcinoma.

\section{CONCLUSION:}

- From the present study it is evident that Histopathological examination of salivary gland lesions stands out to be the most important method in establishing the final diagnosis. It helps in differentiating non neoplastic and neoplastic lesions, as well as in predicting the prognosis, typing, staging and grading of all the neoplasms.

\section{REFERENCES}

1. Dr. Shazia Bashir, et al . Histopathological Spectrum of Salivary Gland Tumors: A 10 Year Experience Scholars Journal of Applied Medical Sciences (SJAMS) Sch. J. App. Med. Sci., 2013; 1(6):1070-1074.

2. Dr Ankur et al. Histopathological spectrum of salivary lesions Research paper vol.3,issuel, january 2014,ISSN No 2277-8179.

3. Archana Shetty ${ }^{*}$, Geethamani.v Spectrum of Major Salivary Gland Tumours: Clinicopathologic Study Sch. J. App. Med. Sci., 2014; 2(3C):10881090

4. Edda A M Vuhahula (2004) salivary gland tumors in uganda: clinical pathological study,African health sciences ,April 1(4);15-23.

5. Ahmd ET AL.(2002).Clinicopathological study of primary salivary gland tumorsin kashmir4(9):231-233. 6. Ellis GL, Auclair PL.

6. Tumors of the salivary glands. Atlas of tumor pathology. WashingtonDC: Armed forces institute of pathology;2006.

7. TP Sajeevan, Joshua Elizabeth, TR Saraswathi, K Ranganathan analysis of salivary gland lesions - an institutional experience RESEARCH ARTICLE Year:2003 | Volume:7 | Issue: 1 | Page:21-2.

8. Akhter J, Hirachand S, Lakhey M : Role of FNAC in the diagnosis of salivary gland swellings : Kathmandu University Medical Journal (2008), Vol.6, No.2, Issue 22, 204-208.

9. Khandekar M.M,Kavatkar A.N,Patankar SA,Bagwan IB,Puranik SC,Deshmukh SD :FNAC of salivary gland lesions with histopathological correlation;Indian journal of otolaryngology \& Head and Neck surgery vol 58 ,No.7. 